\title{
GAYA BAHASA DALAM NOVEL TEENLIT TRILOGI “D'ANGEL”KARYA LUNA TORASHYNGU
}

\author{
Amelia Rosalina, Suryadi, dan Irma Diani \\ Program Studi Pendidikan Bahasa dan Sastra Indonesia \\ Jurusan Pendidikan Bahasa dan Seni \\ FKIP Universitas Bengkulu \\ ameliarosalina@yahoo.com
}

\begin{abstract}
Abstrak
Tujuan penelitian ini adalah untuk mendeskripsikan gaya bahasa yang terdapat dalam novel teenlit "D'Angel Princess" karya Luna Torashyngu. Metode yang digunakan dalam penelitian ini adalah metode deskriptif kualitatif. Data dalam penelitian ini berupa gaya bahasa pada novel teenlit "D'Angel Princess" karya Luna Torashyngu.Teknik pengumpulan data menggunakan teknik dokumentasi. Teknik analisis data dalam penelitian ini dilakukan melalui langkah-langkah, yaitu: (1) membaca novelteenlit "D'Angel Princess" karya Luna Torashyngu(2) mengidentifikasi data, (3) mengklasifikasikan data, (4) menganalisis data, dan (5) menyimpulkan. Uji keabsahan data yang digunakan adalah uji kredibilitas yang dilakukan dengan cara peningkatan ketekunan dengan dosen pembimbing selama proses bimbingan berlangsung, dan diskusi dengan teman sejawat. Hasil penelitianyang ditemukan pada novel D'Angel Princess karya Luna Torashyngu pada pemakaian bahasa gaul dan tidak baku digunakan untuk menonjolkan ciri khas dari novel remaja, kemudian kata denotasi dan konotasi digunakan pengarang untuk memperkuat dan meyakinkan pembaca ketika menyampaikan narasi dan deskripsi dalam cerita, pemakaian kata kajian berfungsi sebagai sarana untuk untuk mononjolkan tema novel yang bertemakan ilmiah, kata asing digunakan ketika tokoh remaja saling berinteraksi untuk menonjolkan kesan gaya remaja yang terlihat gaul. Pemakaian kalimat aktif digunakan untuk mendeskripsikan tokoh sebagai pelaku utama. Pemakaian kalimat pasif digunakan ketika tokoh tidak berperan sebagai pelaku utama di dalam kalimat. Kalimat yang dilesapkan digunakan pengarang ketika menyampaikan deskripsi dan narasi agar cerita lebih terlihat menarik dan mudah dipahami. Kalimat topik komen digunakan untuk memberikan kesan yang indah atau komentar yang indah terhadap tokoh. Pemakaian kalimat minor digunakan untuk memberikan penekanan dan kesungguhan terhadap apa yang dituturkan oleh tokoh agar pembaca ikut merasakan keyakinan. Kalimat minor dan resiprokal digunakan pengarang ketika menyampaikan narasi dalam keadaan atau suasana yang serius.
\end{abstract}

\section{Kata Kunci: gaya bahasa, novel teenlit, "D’Anggel” karya Luna Torashyngu}

\begin{abstract}
Abstact
The purpose of this study is to describe the quality of the language available in the novel teenager "D'Angel Princess" by Luna Torashyngu. The method used in this research is descriptive qualitative method. Data in this study Various styles on the novel teenagers "D'Angel Princess" by Luna Torashyngu. Documentation technique is used in the data collection technigue. Data analysis technique in this research is done through steps, that is: (1) reading novelteenlit "Angel Angel" by Luna Torashyngu (2) hiding data, (3) classifying data, (4) analyzing data, and (5) conclude. Test the validity of the data is a credibility test
\end{abstract}


conducted by increasing persistence with the supervisor during the process, and discussion with colleagues. The results found in the novel D'Angel Princess by Luna Torashyngu in slang and not used to separate the characteristics of the teen novel. Then the word denotation and author connotation to express and convince the compiler readers convey narration and description in the story, said Science used as a means to monetize a novel theme with a scientific theme, the words used to sort out teenage characters who look slang. The use of sentences is used to describe the main character in the sentence Usage. The author's written sentence contains descriptions and narrations to make the story more interesting and easy to understand. Comment topic sentence gives a beautiful impression or a beautiful comment on the characters. Use of minor sentences is used to give challenge and sincerity to what people say so that readers feel confidence. Minor sentences and reciprocal is used by writers when delivering narration in serious situations or moods.

\section{Keywords: language style, teenlit novel, "D'Anggel" by Luna Torashyngu}

\section{PENDAHULUAN}

Bahasa berfungsi sebagai alat komunikasi dan interaksi antarmanusia dalam kehidupannya. Melalui bahasa manusia dapat mengungkapkan segala sesuatu yang ada di dalam diri, baik berbentuk perasaan, pikiran, dan gagasan. Pada saat berinteraksi tentu kita akan memilih bahasa yang tepat sesuai dengan situasi dan kondisi yang dihadapi. Bahasa mengalami perubahan sesuai dengan perubahan masyarakat. Bahasa digunakan sesuai dengan keperluannya sehingga menyebabkan munculnya ragam bahasa.

Kridalaksana (2008:22) menyatakan bahwa ragam bahasa adalah variasi bahasa menurut pemakaian yang berbeda-beda, menurut topik yang dibicarakan, menurut hubungan pembicara, kawan bicara, orang yang dibicarakan, dan menurut pembicara. Dengan kata lain, variasi atau ragam bahasa terjadi sebagai akibat dari adanya keragaman sosial dan keragaman fungsi bahasa (Chaer, 2010:62).

Dalam bidang karya sastra pemakaian bentuk bahasa sangat dipilih agar menghasilkan suatu cerita yang menarik dan dapat memberikan kesenangan serta kenikmatan kepada pembacanya.Salah satu jenis karya yang menggunakan ragam bahasa sastra adalah novel. Novel teenlitD'Angel karya Luna Torashyngu merupakan salah satu hasil dari karya sastra seorang pengarang yang mempergunakan bahasa untuk keperluan bidang sastra. Novel teenlit merupakan sastra populer yang bertemakan kehidupan remaja.

Dalam novel teenlit, hampir keseluruhan pilihan kata atau diksi menggunakan bahasa gaul yang bersifat tidak resmi. Bahasa gaul merupakan salah satu bentuk (genre) foklor yang merupakan sebuah kata tidak lazim di dalam bahasa Nasional Indonesia yang resmi (Sahertian, 2000:2). Misalnya sebutan Ayah dan Ibu diganti dengan bahasa gaul bokap dan nyokap. Bahasa ini jelas tidak sesuai dengan kaidah ejaan Bahasa Indonesia yang sesungguhnya. Pemakaian bahasa gaul ini digunakan pengarang untuk menimbulkan kesan yang menarik agar pembaca mampu menyelami dan menikmati cerita yang dikisahkan dalam dunia remaja. 


\section{Diksi (Pilihan Kata)}

Gaya bahasa sebagai bagian dari diksi bertalian dengan ungkapan-ungkapan yang individual atau karakteristik yang memiliki nilai artistik yang tinggi (Keraf, 2006:23). Diksi yaitu pilihan kata yang tepat dan selaras dalam penggunaannya untuk mengungkapkan gagasan sehingga diperoleh efek tertentu seperti yang diharapkan.

\section{a. Pemakaian Bahasa Gaul}

Bahasa gaul adalah ragam bahasa Indonesia nonstandar yang sering digunakan oleh kaum remaja Indonesia. Menurut Sahertian (2000:2) bahasa gaul adalah salah satu bentuk (genre) foklor yang disebut "ujaran rakyat". Dalam ujaran rakyat, ia termasuk dalam bentuk yang disebut slang (ucapan populer yang merupakan sebuah kata yang tidak lazim di dalam bahasa Nasional Indonesia yang resmi. Biasanya, bahasa gaul ini diucapkan dengan nada atau intonasi tertentu, sehingga terasa lucu, ringan, dan ekpresif (Sahertian, 2000:12).

\section{b. Pemakaian kata tidak baku}

Kata tidak baku adalah kata yang digunakan tidak sesuai dengan pedoman atau kaidah bahasa Indonesia yang sudah ditentukan (Kusumaningsih, 2013:28). Kata tidak baku digunakan saat percakapan sehari-hari atau dalam situasi santai. Penggantian huruf, penambahan awalan, atau akhiran membuat kata tersebut menjadi tidak baku.

\section{c. Pemakaian Kata Bermakna Denotasi dan Konotasi \\ Menurut Putrayasa (2010:8) makna} denotasi adalah makna kata yang tidak mendapat tambahan makna atau perasaan tambahan sedikit pun, atau bisa sedikit pula makna denotasi ini adalah makna yang sebenarnya.

\section{d. Pemakaian Kata Kajian}

Menutut Putrayasa (2010:8) kata kajian merupakan kata yang perlu ditelaah lebih jauh lagi maknanya karena tidak bisa langsung dipahami oleh semua orang. Kata-kata ini hanya dipahami oleh sebagian kaum terpelajar atau kalangan atas terutama dalam tulisan ilmiah dan susah dipahami oleh masyarakat biasa.

\section{e. Pemakaian Bahasa Asing}

Bahasa asing merupakan sebuah bahasa yang bukan berasal dari tempat tertentu (Adawiyah, 2009:3). Misalnya orang yang tinggal di Indonesia berbicara dengan menggunakan bahasa Inggris hal itu disebut dengan bahasa asing.

\section{Kalimat}

Setiyanto (2007:183) mengungkapkan kalimat adalah rangkaian beberapa kata yang menyatakan gagasan, pikiran orang berupa keterangan, pertanyaan, permintaan, atau masalah lain. Pendapat lain dikemukakan oleh Finoza (2008: 141) yang menyatakan kalimat merupakan bagian ujaran/tulisan yang mempunyai struktur minimal subjek (S) dan predikat (P) dan intonasi finalnya menunjukan bagian ujaran/tulisan itu sudah lengkap dengan makna (bernada berita, tanya atau perintah).

Jenis Kalimat

\section{a. Kalimat Aktif}

Menurut Mulyono (2012:61) kalimat aktif ialah kalimat yang subjeknya melakukan pekerjaan yang dinyatakan oleh predikatnya. Artinya, kalimat jenis ini bersubjek pelaku pekerjaan, atau subjek bermakna melakukan pekerjaan. Karena itu subjek yang bermakna seperti itu disebut unsur aktor dan predikatnya disebut unsur aksi.

b. Kalimat Pasif

Menurut Mulyono (2012:63) Kalimat pasif ialah kalimat yang subjeknya dikenai 
pekerjaan yang dinyatakan predikat. Dengan begitu, secara sistemantis, subjek kalimat pasif merupakan subjek menderita.

c. Kalimat Medial

Menurut Mulyono (2012:65) Kalimat medial ialah kalimat yang berpredikat kata kerja transitif dengan objek diri subjeknya sendiri.

\section{d. Kalimat Resiprokal}

Menurut Mulyono (2012:65) Kalimat resiprokal ialah kalimat yang berpredikat kata kerja yang menyatakan makna 'saling'.

\section{e. Kalimat Minor}

Menurut Mulyono (2012:99) kalimat minor adalah kalimat yang hanya terdiri atas satu unsur inti kalimat, yaitu unsur subjek atau predikat saja.

\section{f. Kalimat Topik-Komen}

Menurut Sarwoko (2007:111) kalimat topik adalah kalimat utama yang berisi inti gagasan dari sebuah paragraf atau bacaan. Kalimat komen adalah kalimat yang menjelaskan topik untuk mengembangkan paragraf atau kalimat penjelas dari kalimat utama. Sarwoko (2007:111) membagi kalimat ini menjadi dua, topik dan sebutan.

\section{g. Pelesapan}

Menurut Sarwoko

(2007:104)

pelesapan merupakan penghilangan salah satu unsur yang sama atau hampir sama dalam sebuah kalimat sebab unsur tersebut hanya membuat kalimat menjadi lebih panjang.

\section{METODE}

Penelitian ini merupakan penelitian kualitatif. Metode kualitatif digunakan untuk mendapatkan data yang mendalam, suatu data yang mengandung makna. Makna adalah data yang sebenarnya, data yang pasti yang merupakan suatu nilai di balik data yang tampak (Sugiyono, 2005:3).
Menurut Patilima (2007:57) penelitian kualitatif bersifat deskriptif dalam arti peneliti tertarik proses, makna, dan pemahaman yang di dapat melalui kata atau gambar. Pada penelitian ini yang diamati merupakan kalimat dan kata-kata yang mengandung unsur gaya bahasa.

Data dalam penelitian ini berupa gaya bahasa berdasarkan diksi dan kalimat dalam novel D'Angel Princess karya Luna Torashyngu.Sumber data penelitian ini adalah novel D'Angel Princess karya Luna Torashyngu dengan jumlah halaman 288, terbitan PT. Gramedia Pustaka Utama, Jakarta.

Menurut Sugiyono (2005:62) teknik pengumpulan data merupakan langkah yang paling strategis dalam penelitian, karena tujuan utama dari penelitian adalah mendapatkan data. Tanpa mengetahui teknik pengumpulan data, maka peneliti tidak akan mendapatkan data yang memenuhi standar data yang diterapkan.Analisis yang dilakukan dalam penelitian ini dilakukan melalui langkahlangkah (1) Membaca novel D'Angel Princess karya Luna Torashyngu, (2) Mengidentifikasi data dengan memberikan kode pada setiap teks yang termasuk ke dalam jenis wujud diksi dan kalimat. Misalnya D'AP/H.7 artinya, D'AP yaitu D'Angel Princess pada halaman 7, (3) Mengklasifikasikan data, yaitu data yang telah diidentifikasi diklasifikasikan berdasarkan wujud diksi dan kalimat, (4) Menganalisis data berdasarkan jenis diksi dan kalimat dalam novel D'Angel Princess karya Luna Torashyngu, (5) Menyimpulkan, yaitu kegiatan menyimpulkan hasil analisis merupakan kegiatan terakhir dalam penelitian yang mendapatkan hasil dari proses yang telah dilakukan.

\section{HASIL DAN PEMBAHASAN}

Pada bab ini diuraikan data hasil penelitian dan pembahasan. Berdasarkan hasil penelitian penulis menemukan 
pemakaian bahasa gaul dan tidak baku yang jelas digunakan pengarang untuk menonjolkan ciri khas dari novel remaja, kemudian kata denotasi dan konotasi digunakan pengarang untuk memperkuat dan meyakinkan pembaca ketika menyampaikan narasi dan deskripsi dalam cerita, pemakaian kata kajian digunakan pengarang yang berfungsi sebagai sarana untuk untuk mononjolkan tema novel yang bertemakan ilmiah, kata asing digunakan ketika tokoh remaja saling berinteraksi, hal ini digunakan untuk menonjolkan kesan gaya remaja yang terlihat gaul.

Kalimat aktif digunakan untuk mendeskripsikan apa yang dilakukan tokoh dalam novel. Pemakaian kalimat pasif digunakan ketika tokoh tidak berperan sebagai pelaku utama di dalam kalimat. Kalimat yang dilesapkan digunakan pengarang ketika menyampaikan deskripsi dan narasi agar cerita lebih terlihat menarik dan mudah dipahami. Kalimat topik komen digunakan untuk memberikan kesan yang indah atau komentar yang indah terhadap tokoh. Pemakaian kalimat minor digunakan untuk memberikan penekanan dan kesungguhan terhadap apa yang dituturkan oleh tokoh agar pembaca ikut merasakan keyakinan. Kalimat minor dan resiprokal digunakan ketika tokoh dalam keadaan atau suasana yang serius.

Contoh diksi dan kalimat dalam"Novel Teenlit"D'Angel" Karya Luna Torashyngu". Konteks pada data 1 terjadi di Bandar Udara Makassar antara Fika, Mama Fika, Gya, dan pengawal Gya. Saat itu Gya ingin berjalan-jalan disekitar bandara sambil menunggu mamanya yang sedang mengurus tiket. Tapi tiba-tiba saja ada seorang anak yang seusianya menabrak Fika yang bernama Gya. Gya yang jatuh saat itu marah-marah serta berbicara dengan nada kesal.

Wujud gaya bahasa pada konteks di atas berdasarkan penggunaan diksi dalam novel D'Angel Princess karya Luna
Torashyngu (1) Mama kok lama sih? (2) Ketidakberesan itu membuat mereka nggak dapet pesawat saat transit di Makassar.

Pada kutipan (1) tuturan disampaikan Fika ketika menunggu mamanya yang tidak kunjung kembali dengan menggunakan bahasa gaul partikel [kok] yang merupakan kata tanya pengganti 'kenapa', lalu Fika juga menggunaan partikel [sih] yang saat itu merupakan penegasan Fika dalam kalimat yang di ujarkannya dengan ekspresi kesal, Fika tidak menggunakan bahasa yang baku ketika berbicara dengan dirinya sendiri, ia menggunakan gaya bahasa yang gaul dikarenakan faktor usianya yang masih remaja. Kata tidak baku 'nggak' yang merupakan asal dari kata 'tidak', kata ini dipotong tiga huruf di awal tid dan diganti dengan huruf ngg sehingga menjadi nggak pergantian huruf ini menyebabkan kata menjadi tidak baku.

Kutipan (2) digunakan pengarang ketika menyampaikan narasinya menggunakan kata tidak baku [nggak] dan [dapet] terdapat pergantian huruf pada kata ini yang menyebabkan kata menjadi tidak baku yaitu dipotong tiga huruf awal pada kata 'tidak' menjadi ' $a k$ ' lalu diganti dengan huruf ' $n g g^{\prime}$ sehingga menjadi 'nggak', kemudian pada kata 'dapat' huruf ' $a$ ' di ganti dengan huruf ' $e$ ' menjadi 'dapet' pergantian huruf tersebut tentu saja menjadikan kata menjadi tidak baku. Lalu pada kutipan tersebut pengarang juga menggunakan kata kajian [transit] yang memiliki arti melewati bandar udara lain sebelum bandar udara tujuan, kata [transit] ini hanya dipahami oleh kalangan tertentu saja dan tidak dipahami oleh masyarakat biasa.

Wujud gaya bahasa berdasarkan penggunaan kalimat dalam novel D'Angel Princess karya Luna Torashyngu (3) Fika melihat penabraknya yang terduduk di lantai, (4) Tapi, Oom! Bukan saya yang nabrak. 
Pada kutipan (3) digunakan pengarang ketika mendeskripsikan Fika yang melihat seseorang terjatuh, pengarang menggunakan kalimat aktif transitif [melihat] dengan kata dasar 'lihat' kemudian mendapat prefiks me- menjadi [melihat]. Kutipan (4) dituturkan Fika kepada pengawal Gya ketika membela dirinya, kalimat yang dituturkan Fika tersebut mengalami pelesapan imbuhan pada kata kerja berawalan me- yaitu [nabrak] yang semestinya adalah [menabrak] sehingga membuat kalimat yang dituturkan Fika menjadi tidak baku, pada tuturan ini Fika tidak menggunakan bahasa gaul melainkan menggunakan bahasa yang santun kepada mitra tuturnya, hal ini dikarenakan Fika melihat lawan bicaranya yang beda usia dengannya. Terlihat pada tuturan ini, Fika menggunaan kata [om] yang berarti [paman] lalu penggunaan kata [saya] merupakan tuturan yang santun kepada orang yang lebih tua.

Pada hasil penelitianpemakaian bahasa gaul dan tidak baku digunakan untuk menonjolkan ciri khas dari novel remaja, kemudian kata denotasi dan konotasi digunakan pengarang untuk memperkuat dan meyakinkan pembaca ketika menyampaikan narasi dan deskripsi dalam cerita, pemakaian kata kajianberfungsi sebagai sarana untuk untuk mononjolkan tema novel yang bertemakan ilmiah, kata asing digunakan ketika tokoh remaja saling berinteraksiuntuk menonjolkan kesan gaya remaja yang terlihat gaul.Pemakaian kalimat aktif digunakan untuk mendeskripsikantokoh sebagai pelaku utama. Pemakaian kalimat pasif digunakan ketika tokoh tidak berperan sebagai pelaku utama di dalam kalimat. Kalimat yang dilesapkan digunakan pengarang ketika menyampaikan deskripsi dan narasi agar cerita lebih terlihat menarik dan mudah dipahami. Kalimat topik komen digunakan untuk memberikan kesan yang indah atau komentar yang indah terhadap tokoh. Pemakaian kalimat minor digunakan untuk memberikan penekanan dan kesungguhan terhadap apa yang dituturkan oleh tokoh agar pembaca ikut merasakan keyakinan. Kalimat minor dan resiprokal digunakan pengarang ketika menyampaikan narasi dalam keadaan atau suasana yang serius.

\section{PENUTUP \\ Kesimpulan}

Berdasarkan hasil penelitian yang telah di lakukan mengenai gaya bahasa dalam novel " $D$ 'Angel Princess" karya Luna Torashyngu, penulis menarik kesimpulan bahwa Luna Torashyngu memiliki ciri khas gaya bahasa yang seringkali menggunakan jenis diksi yang berbeda dalam satu kalimat. Dalam novel D'Angel Princess karya Luna Torashyngu sering menggunakan kata asing dan kata kajian yang digunakan dalam satu kalimat sehingga menimbulkan kesan yang berbeda dari novel teenlit lainnya.

\section{Saran}

Penelitian ini membahas mengenai gaya bahasa berdasarkan wujud diksi dan kalimat pada novel "D'Angel Princess" karya Luna Torashyngu. Penulis mengharapkan terdapat penelitian selanjutnya mengenai gaya bahasa khususnya terhadap novel teenlit sehingga dapat ditemukan gaya bahasa yang berbeda dari novel teenlityang tidak ditemukan pada novel "D'Angel Princess" karya Luna Torashyngu. Kepada siswa maupun guru, agar dapat menggunakan penelitian ini sebagai salah satu sumber referensi dalam pembelajaran terutama untuk memahami gaya bahasa berdasarkan diksi dan kalimat yang terdapat di dalam novel teenlit dan juga sebagai inspirasi untuk melakukan penelitian yang lebih mendalam. 


\section{DAFTAR PUSTAKA}

Dewojati, C. 2010. Wacana Hedonisme dalam Sastra Populer Indonesia. Yogyakarta: Pustaka Belajar.

Finoza, L. 2008. Komposisi Bahasa Indonesia. Jakarta: Diksi Insan Mulia.

Kridalaksana, H. 2008. Kamus Linguistik Edisi Keempat. Jakarta: Gramedia Pustaka Utama.

Kusumaningsih, D. dkk. (2013). Terampil Berbahasa Indonesia. Yogyakarta: Penerbit ANDI.

Keraf, G. 2006. Diksi dan Gaya Bahasa. Jakarta: PT Gramedia Pustaka Utama.
Putrayasa, I. B. 2009. Jenis Kalimat dalam Bahasa Indonesia. Bandung: PT Refika Aditama.

Sahertian, D. 2000. Kamus Bahasa Gaul. Jakarta: Pustaka Sinar Harapan.

Sugiyono. 2005. Memahami Penelitian Kualitatif. Bandung: ALFABETA.

Sugiyono. 2014. Metode Penelitian Kuantitatif, Kualitatif, dan $R$ \& $D$. Bandung: Alfabeta.

Tarigan, H. G. 2013. Pengajaran Gaya Bahasa. Bandung: CV Angkasa. 